GRASAS Y ACEITES 67 (2)

April-June 2016, e136

ISSN-L: 0017-3495

doi: http://dx.doi.org/10.3989/gya.0757152

\title{
Differentiation of partial acylglycerols derived from different animal fats by EA-IRMS and GCMS techniques
}

\author{
A.N. Nina Naquiah ${ }^{\mathrm{a}}$, J.M.N. Marikkar ${ }^{\mathrm{a}, \mathrm{b}, \varpi}$ and M. Shuhaimi ${ }^{\mathrm{a}}$ \\ ${ }^{a}$ Halal Products Research Institute, Universiti Putra Malaysia, 43400 UPM Serdang, Selangor D.E., Malaysia \\ ${ }^{b}$ International Institute for Halal Research \& Training, International Islamic \\ University Malaysia P.O. Box 10, 50728 Kuala Lumpur, Malaysia \\ ${ }^{\square}$ Corresponding author: nazrim@iium.edu.my
}

Submitted: 15 July 2015; Accepted: 22 December 2015

SUMMARY: A study was carried out to compare partial acylglycerols of lard with those of chicken fat, beef fat and mutton fat using Gas Chromatography Mass Spectrometry (GC-MS) and Elemental Analysis-Isotope Ratio Mass Spectrometry (EA-IRMS). Mono- (MAG) and di-(DAG) acylglycerols of animal fats were prepared according to a chemical glycerolysis method and isolated using column chromatography. The fatty acid composition and $\delta^{13} \mathrm{C}$ carbon isotope ratio of MAG and DAG derived from individual animal fat were determined separately to establish their identity characteristics. The results showed that the $\delta^{13} \mathrm{C}$ values of MAG and DAG of lard were significantly different from those of MAG and DAG derived from chicken fat, beef fat and mutton fat. According to the loading plots based on a principle component analysis (PCA), fatty acids namely stearic, oleic and linoleic were the most discriminating parameters to distinctly identify MAG and DAG derived from different animal fats. This demonstrated that the EA-IRMS and the PCA of fatty acid data have considerable potential for discriminating MAG and DAG derived from lard from other animal fats for Halal authentication purposes.

KEYWORDS: Animal fat derivatives; DAG; EA-IRMS; GC-MS; MAG; Partial acylglycerols

RESUMEN: Diferenciación de acilgliceroles parciales derivados de diferentes grasas animales mediante técnicas de EA-IRMS y GCMS. Se realizó un estudio para comparar acilgliceroles parciales de la manteca de cerdo con las de grasa de pollo, grasa de vacuno y grasa de cordero utilizando cromatografía de gases-espectrometría de masas (GC-MS) y análisis elemental de Isótopos-Espectrometría de Masas (EA-IRMS). Los mono- (MAG) y di- (DAG) acilgliceroles de grasas animales se prepararon mediante un método de glicerolisis química y se aislaron mediante cromatografía en columna. La composición de ácidos grasos y la relación isotópica de carbono $\delta^{13} \mathrm{C}$ de los MAG y DAG de las grasas de animales se determinan por separado para establecer sus características de identidad. Los resultados mostraron que los valores de $\delta^{13} \mathrm{C}$ de MAG y DAG de la manteca de cerdo fue significativamente diferente de los de MAG y DAG derivados de grasa de pollo, grasa de vacuno y grasa de cordero. De acuerdo con los diagramas de carga basados en el análisis de componentes principales (PCA), los ácidos grasos esteárico, oleico y linoleico fueron los parámetros más exigentes para identificar claramente MAG y DAG derivados de las diferentes grasas animales. Esto demuestra que EA-IRMS y PCA de los datos de ácidos grasos tienen un potencial considerable en discriminar MAG y DAG derivados de la manteca de cerdo frente a otras grasas animales para fines de autenticación Halal.

PALABRAS CLAVE: Acilgliceroles parciales; DAG; Derivados de grasas animales; EA-IRMS; GC-MS; MAG

Citation/Cómo citar este artículo: Nina Naquiah AN, Marikkar JMN, Shuhaimi M. 2015. Differentiation of partial acylglycerols derived from different animal fats by EA-IRMS and GCMS techniques. Grasas Aceites 67 (2): e136. doi: http://dx.doi.org/10.3989/gya.0757152.

Copyright: (C) 2016 CSIC. This is an open-access article distributed under the terms of the Creative Commons Attribution-Non Commercial (by-nc) Spain 3.0 Licence. 


\section{INTRODUCTION}

Partial acylglycerols are esters of glycerols with either one or two of the hydroxyl groups esterified with fatty acids. With hydroxyl groups in the structure, partial acylglycerols display remarkable surface activity, which enables them to reduce surface tension at the oil-water interface (De Man, 1999). Industrial production of partial acylglycerols involves many different approaches. The most direct route to produce partial acylglycerols is the partial hydrolysis of the triacylglycerols present in natural oils and fats. The esterification of glycerol with different fatty acids could be another approach, but might require preliminary hydrolysis to produce free fatty acids from raw materials (Rezaie and Temelli, 2000). Although plant lipids were the most common raw material for partial acylglycerol production, animal fats were also employed as an alternative option. In a previous report, Sudraud et al. (1981) pointed out that some of the commercially available MAG and DAG could have been derived from hydrogenated lard. This was reaffirmed subsequently by Cheong et al. (2009) who demonstrated the potential value of lard as a raw material for the production of partial acylglycerols. Although the utilization of animal fat in industrial products could be beneficial for the animal carcass industry, the use of animal-derived ingredients in food might not be desirable due to food taboos based on certain religious restrictions (Riaz and Chaudhary, 2004).

Studies on the synthesis, isolation and characterization of partial acylglycerols have been the interest of many researchers over the past several years (Cheng et al., 2005). Deng et al. (2008) demonstrated an HPLC-based method for the separation of isomers of monoacylglycerols (i.e. sn-1-MAG, sn-2-MAG and sn-3-MAG) having the same acyl groups. Gil and co-workers (2007) were able to isolate and characterize five new monoacylglycerols (MAGs) that were isolated from the marine sponge Stelletta $s p$. using RP-HPLC and atom bombardment mass spectrometry. In another study, Destaillats et al. (2010) completed the structural elucidation of alpha- and beta-regio-isomers of monopalmitoyl-glycerol (MAG C16:0) using gas chromatography-mass spectrometry. As the use of food ingredients derived from swine is prohibited under halal food regulations, researchers were interested to find ways of detecting lard based partial acylglycerols. Although the characterization of partial acylglycerols of some vegetable oils have been done using fatty acids, a more complete profiling of various other physcio-chemical characteristics using a variety of analytical techniques is still necessary. Isotope ratio mass spectrometry (IRMS), for instance, has been proven to be a useful analytical tool for various food authentication purposes. According to past studies, IRMS has been proven to be useful in tracing the origin of various biological substances.
For instance, it has been employed to detect the adulteration of honey (Chesson et al., 2011; Simsek et al., 2012), differentiate farm and wild salmon species (Aursand et al., 2000) and test the authenticity of vegetable oils namely sunflower oil, corn oil, groundnut oil, palm oil, rapeseed oil and olive oil (Kelly et al., 1997; Bianchi et al., 1993). However, studies dealing with the combined application of IRMS and GC-MS to differentiate partial acylglycerols are still limited. Hence, the objective of this study was to assess the use of EA-IRMS along with GC-MS to differentiate partial acylglycerols of lard from those derived from other animal fats namely beef, mutton, and chicken fats.

\section{MATERIALS AND METHODS}

\subsection{Materials}

Samples of animal fats namely lard, beef fat, mutton fat, and chicken fat were extracted by rendering three samples of adipose tissues of animals collected from local slaughter houses located in the Bangi, Serdang and Kajang areas of Malaysia according to the method reported previously by Marikkar et al. (2001). Analytical grade chemicals of glycerol, hexane, diethyl ether, chloroform and sodium hydroxide pellets were obtained from Merck Chemicals, Germany. A set of FAME standard comprising 37 fatty acids ( $\mathrm{C} 4$ to $\mathrm{C} 24)$ and a monoacylglycerol stock solution were purchased from Sigma-Aldrich Chemicals (Deisenhofen, Germany).

\subsection{MAG and DAG preparation}

Chemical glycerolysis of animal fats was performed in triplicate according to the procedure described by Indrasti et al. (2010). For the glycerolysis reaction, a 35-g fat sample was mixed with $15 \mathrm{~g}$ of a glycerine solution and a $0.2 \mathrm{~g}$ portion of sodium hydroxide. The mixture was then heated at $250{ }^{\circ} \mathrm{C}$ with vigorous mixing for $60 \mathrm{~min}$. The separation of glycerolysis products into MAG and DAG was carried out according to the AOCS method $\mathrm{Cd}$ 11c- 93 (AOCS, 2007) using a glass column filled with Davison 923 type silica gel (Sigma Aldrich). Thin layer chromatography was run subsequently to verify the purity of the fractions collected from column chromatography.

\subsection{Determination $\delta^{13} \mathrm{C}$ of bulk animal fats}

About $0.2 \mu \mathrm{g}$ of partial acylglycerol of individual animal fat was weighed and loaded into a clean tin capsule to determine their $\delta^{13} \mathrm{C}$ values. The capsules containing samples were placed onto the autosampler system of an elemental analyzer (Europa Scientific, UK) for burning in an $\mathrm{O}_{2}$ atmosphere of the combustion $\mathrm{CuO}$ tube with its temperature set 
at $960^{\circ} \mathrm{C}$. Combustion gases were eluted through a reduction column by a stream of He gas and passed into the gas chromatograph where $\mathrm{CO}_{2}$, still in the He stream, was separated from the other gases. The gas stream was then entered into the IRMS system (Sercon Ltd., Crewe, U.K.) where the $\mathrm{CO}_{2}$ gas was analyzed by comparison with NBS-22 reference material (with a $\delta^{13} \mathrm{C}$ value of $-30.03 \%$ ). During every batch of analyses, an empty tin capsule was analyzed as the blank to check the background (Liu et al., 2007). The results were compared to Vienna Pee Dee Belemnite (V-PDB). The isotopic values were calculated against the international isotope reference standards: NBS-22 (International Atomic Energy Agency, Vienna, Austria) for 13C/12C measurements (Osorio et al., 2011).

\subsection{Preparation of fatty acid methyl esters}

A 50-mg portion of partial acylglycerol was weighed into a $20-\mathrm{mL}$ test tube (with screw cap). After adding a $2 \mathrm{ml}$ portion of $2 \mathrm{~N}$ sodium hydroxide in methanol, the sample tube was closed and heated at $80{ }^{\circ} \mathrm{C}$ for 1 hour. After allowing the tube and its contents to set for a few minutes, a $2 \mathrm{~mL}$ portion of $25 \%$ borontrifluoride solution in methanol was added. The tube was closed and heated again for 1 hour at $80{ }^{\circ} \mathrm{C}$. Subsequently, $5 \mathrm{~mL}$ portions of water and hexane were added into this. The contents of the tube were shaken well and allowed to undergo phase separation. The clear supernatant of the solution was transferred to a 2-mL auto-sampler vial (AOAC, 2007).

\subsection{Determination of fatty acid composition}

The top hexane layer of the FAME solution was injected onto an Agilent $6890 \mathrm{~N}$ gas chromatograph (Agillent Technologies, Singapore) equipped with a polar capillary column RTX-5 $(0.32 \mathrm{~mm}$ internal diameter, $30 \mathrm{~m}$ length and $0.25 \mu \mathrm{m}$ film thickness; Restex Corp., Bellefonte, PA) and a Flame Ionization Detector (FID). Split injection was conducted with a split ratio of 58:1 using nitrogen as carrier gas at a flow-rate of $1.00 \mathrm{~mL} \cdot \mathrm{min}^{-1}$. The temperature of the column was $50{ }^{\circ} \mathrm{C}$ (for $1 \mathrm{~min}$ ), and programmed to increase to $200{ }^{\circ} \mathrm{C}$ at $8^{\circ} \mathrm{C} \cdot \mathrm{min}^{-1}$. The temperatures of the injector and detector were maintained at $200{ }^{\circ} \mathrm{C}$ (Yanty et al., 2011).

\subsection{Statistical analysis}

Data were statistically analyzed by one-way analysis of variance (ANOVA) using MINITAB (version 14) statistical package at the 0.05 probability level. For the grouping and classification of models, PCA was carried out using Unscrambler 9.7 (Camo, USA) software.

\section{RESULTS AND DISCUSSION}

\section{1. $\delta^{13} \mathrm{C}$ values of bulk MAG and DAG derived from animal fats}

The $\delta^{13} \mathrm{C}$ values of MAG and DAG of lard, chicken fat, beef fat and mutton fat are compared as shown in Table 1. The $\delta^{13} \mathrm{C}$ values of MAG and DAG of lard, beef fat, chicken fat and mutton fat have not been investigated previously; therefore there are hardly any reports to compare the $\delta^{13} \mathrm{C}$ value. The highest $\delta^{13} \mathrm{C}$ value of MAG was found in chicken fat $(-20.3 \%$ ) while the lowest value was found for mutton fat $(-31.9 \%)$. The $\delta^{13} \mathrm{C}$ values of MAG of lard $(-22.3 \% 0)$ and beef fat $(-25.0 \% 0)$ were within the range of these two $\delta^{13} \mathrm{C}$ values. In the case of DAG, the highest $\delta^{13} \mathrm{C}$ value of DAG was found for chicken fat $(-19.2 \%)$ while the lowest value was found for mutton fat $(-32.2 \%)$. The $\delta^{13} \mathrm{C}$ values of the DAGs of lard $(-22.2 \%)$ and beef fat $(-24.3 \%$ ) were within the range of these two extremes of the mean $\delta^{13} \mathrm{C}$ values. The statistical analysis of the data from the present study suggested that the determination of $\delta^{13} \mathrm{C}$ value for MAG and DAG can be a useful tool since the $\delta^{13} \mathrm{C}$ value of lard $(-22.9 \%)$ was significantly $(p<0.05)$ different from those of beef fat $(-25.0 \%)$, chicken fat $(-20.3 \%)$, and mutton fat $(-31.9 \%$ ) (Table 1$)$. The observed variation in the $\delta^{13} \mathrm{C}$ values of animal fat could be attributed to their species difference (Osorio et al., 2011), genetic factors (Wood et al., 2008) as well as the diet fed to the animals (Bojlul et al., 2007). According to previous investigators, the variation in the $\delta^{13} \mathrm{C}$ values of oils and fats originating from different plant sources are due to isotopic fractionation during physical, chemical and biological processes in plants (Kelly and Rhodes, 2002).

TABLE 1. $\quad \delta^{13} \mathrm{C}$ values of the MAG and DAG of chicken fat, lard, beef fat and mutton fat

\begin{tabular}{lcccc}
\hline & & & \multicolumn{2}{c}{$\delta^{13} \mathbf{C}(\%)$} \\
\cline { 3 - 5 } MAG & Fat Types & $\boldsymbol{n}$ & Mean & $\boldsymbol{s} \boldsymbol{d}$ \\
& CF & 3 & $-20.3^{\mathrm{d}}$ & 0.38 \\
& LD & 3 & $-22.9^{\mathrm{c}}$ & 0.59 \\
\multirow{4}{*}{ DAG } & BF & 3 & $-25.0^{\mathrm{b}}$ & 0.92 \\
& MF & 3 & $-31.9^{\mathrm{a}}$ & 0.81 \\
& CF & 3 & $-19.2^{\mathrm{d}}$ & 0.51 \\
& LD & 3 & $-22.2^{\mathrm{c}}$ & 0.75 \\
& BF & 3 & $-24.3^{\mathrm{b}}$ & 0.41 \\
& MF & 3 & $-32.2^{\mathrm{a}}$ & 0.33 \\
\hline
\end{tabular}

${ }^{1}$ Means within each column with different superscripts are significantly $(\mathrm{p}<0.05)$ different.

${ }^{2}$ Abbreviations: MAG, monoacylglycerol; DAG, diacylglycerol; LD, Lard; CF, Chicken fat; BF, Beef fat; MF, Mutton fat. 


\subsection{Fatty acid profiles of MAG}

The fatty acid distributional pattern of MAG derived from lard, chicken fat, beef fat and mutton fat are compared as shown in Table 2. The most dominant fatty acid of MAG derived from lard was oleic $(38.75 \%)$, followed by palmitic $(28.16 \%)$ and linoleic $(21.55 \%)$. According to previous reports, this was the distributional order of the major fatty acids of lard (Marikkar \& Yanty, 2014; Yanty et al., 2011). The MAG of chicken fat was also found to have oleic acid (45.94\%) as the most dominant fatty acid, followed by palmitic $(30.99 \%)$ and linoleic $(8.97 \%)$ acids. The MAG of chicken fat differed from that of lard by having a small amount of palmitoleic acid $(6.01 \%)$ in addition to differences in the proportions of other fatty acids. The MAGs derived from beef and mutton fats differed from those of lard and chicken fat by having stearic (31.31-35.34\%) as the major fatty acid (Table 2). For this reason, the MAG of beef fat and mutton fat displayed lower contents of unsaturated fatty acids (30.61 to $39.72 \%$ ) than saturated fatty acids $(60.27$ to $69.39 \%$ ). In fact, there were differences between the MAG of beef fat and mutton fats with regard to the occurrence of myristic and linoleic acids. While some amounts of myristic and linoleic acids were present in the MAG of beef fat, they were totally absent in the MAG of mutton fat. These differences were mainly due to the diverse pattern of distribution of individual fatty acids among animal fats as reported previously (Naquiya et al., 2013). When these data were subjected to an appropriate multivariate data analysis technique, a clear differentiation can be reached. PCA, for instance, is a way of identifying patterns in data, and expressing the data in such a way as to emphasize their similarities and differences (Shin et al., 2010).

As fatty acids, namely myristic (C14:0), palmitic (C16:0), palmitoleic (C16:1), stearic (C18:0), oleic $(\mathrm{C} 18: 1)$ and linoleic $(\mathrm{C} 18: 2)$ acids were found to occur in varying amounts in the MAG of all four animal fats, they were used as independent variables in the PCA procedure. According to Kamal-Eldin and Anderson (1997), visualization of groups by various plotting systems becomes possible if data of at least three measured variables are available. The score plot of the fatty acids of the MAG derived from the MAGs of four animal fats as shown in Figure 1 represents the projection of samples defined by principle component 1 (PC1) and principle component 2 (PC2). PC1 is the linear combination of variables that explains the highest variation among the samples, while PC2 is orthogonal to PC1 and exhibited the second largest variation (Cordella et al., 2003). The score plot projected on PC1 described $89 \%$ of the variation while PC2 accounted for $8 \%$ of the variation, making up $97 \%$ of variance for PC1 and PC2. According to the group separation illustrated in Figure 1, the MAG of mutton fat and beef fat were located in the upper right quadrant and lower right quadrant, respectively. Their positions were well differentiated from the MAGs of lard and chicken fat, which were located in the lower left quadrant, and upper left quadrant, respectively. However, the separation between the MAGs of lard and chicken fat was not remarkable due to their close proximity to each other. Fatty acid variables having high influence on the group separation of the samples in the score plot could be traced from the analysis of the loading plot. As explained by Cordella et al. (2003), a variable which is farther from the origin of the axis contributes most to the variation in the statistical model generated by PCA. According to the loading plot shown in Figure 2, out of the six fatty acid variables, stearic, oleic and linoleic acids were the most discriminating variables that influenced the group separation into four different clusters.

TABLE 2. Fatty acid composition of the MAG and DAG of lard, chicken fat, beef fat and mutton fat ${ }^{1}$

\begin{tabular}{|c|c|c|c|c|c|c|c|c|c|c|}
\hline \multirow{2}{*}{ Fat type } & & \multicolumn{9}{|c|}{ Fatty acid (methyl esters) (\%) } \\
\hline & & C14:0 & C16:0 & C16:1 & C18:0 & C18:1 & C18:2 & C20:0 & ¿ SFA & ¿ USFA \\
\hline \multirow[t]{4}{*}{ MAG } & LD & nd & $28.16 \pm 0.00^{\mathrm{a}}$ & nd & $11.54 \pm 0.03^{\mathrm{b}}$ & $38.75 \pm 0.02^{\mathrm{b}}$ & $21.55 \pm 0.04^{\mathrm{a}}$ & nd & 39.7 & 60.3 \\
\hline & $\mathrm{CF}$ & nd & $30.99 \pm 0.02^{\mathrm{a}}$ & $6.01 \pm 0.01^{\mathrm{a}}$ & $8.09 \pm 0.00^{\mathrm{b}}$ & $45.94 \pm 0.03^{\mathrm{a}}$ & $8.97 \pm 0.00^{\mathrm{b}}$ & nd & 39.08 & 60.92 \\
\hline & $\mathrm{BF}$ & $5.90 \pm 0.01^{\mathrm{a}}$ & $28.16 \pm 0.04^{\mathrm{a}}$ & nd & $35.34 \pm 0.05^{\mathrm{a}}$ & $24.83 \pm 0.04^{\mathrm{c}}$ & $5.77 \pm 0.04^{\mathrm{b}}$ & nd & 69.39 & 30.61 \\
\hline & MF & nd & $28.96 \pm 0.05^{\mathrm{a}}$ & nd & $31.31 \pm 0.10^{\mathrm{a}}$ & $39.72 \pm 0.14^{\mathrm{b}}$ & nd & nd & 60.27 & 39.72 \\
\hline \multirow[t]{4}{*}{ DAG } & $\mathrm{LD}$ & $0.79 \pm 0.91^{\mathrm{b}}$ & $31.35 \pm 1.38^{\mathrm{a}}$ & $0.86 \pm 1.00^{\mathrm{b}}$ & $14.92 \pm 0.62^{\mathrm{c}}$ & $40.29 \pm 0.79^{\mathrm{b}}$ & $11.79 \pm 0.32^{\mathrm{a}}$ & nd & 47.06 & 52.94 \\
\hline & $\mathrm{CF}$ & $0.80 \pm 0.10^{\mathrm{b}}$ & $31.36 \pm 2.63^{\mathrm{a}}$ & $5.71 \pm 0.33^{\mathrm{a}}$ & $7.85 \pm 0.26^{\mathrm{d}}$ & $47.24 \pm 1.55^{\mathrm{a}}$ & $5.92 \pm 3.58^{\mathrm{b}}$ & $1.12 \pm 1.29^{\mathrm{a}}$ & 41.13 & 58.87 \\
\hline & $\mathrm{BF}$ & $4.89 \pm 0.09^{\mathrm{a}}$ & $25.56 \pm 0.08^{\mathrm{b}}$ & $1.14 \pm 0.12^{\mathrm{b}}$ & $38.57 \pm 0.53^{\mathrm{a}}$ & $28.28 \pm 0.33^{\mathrm{c}}$ & $1.57 \pm 0.20^{\mathrm{c}}$ & nd & 69.02 & 30.99 \\
\hline & $\mathrm{MF}$ & nd & $27.38 \pm 0.08^{\mathrm{b}}$ & nd & $36.49 \pm 0.28^{\mathrm{b}}$ & $36.13 \pm 0.36^{\mathrm{b}}$ & nd & nd & 63.87 & 36.13 \\
\hline
\end{tabular}

${ }^{1}$ Each fatty acid value in the table represents the means \pm standard deviations of three replicates. Means within each column with different superscripts are significantly $(\mathrm{p}<0.05)$ different. ${ }^{2}$ Abbreviations: MAG, monoacylglycerol; DAG, diacylglycerol; LD, Lard; CF, Chicken fat; BF, Beef fat; MF, Mutton fat; SFA, saturated fatty acid; USFA, unsaturated fatty acid. 


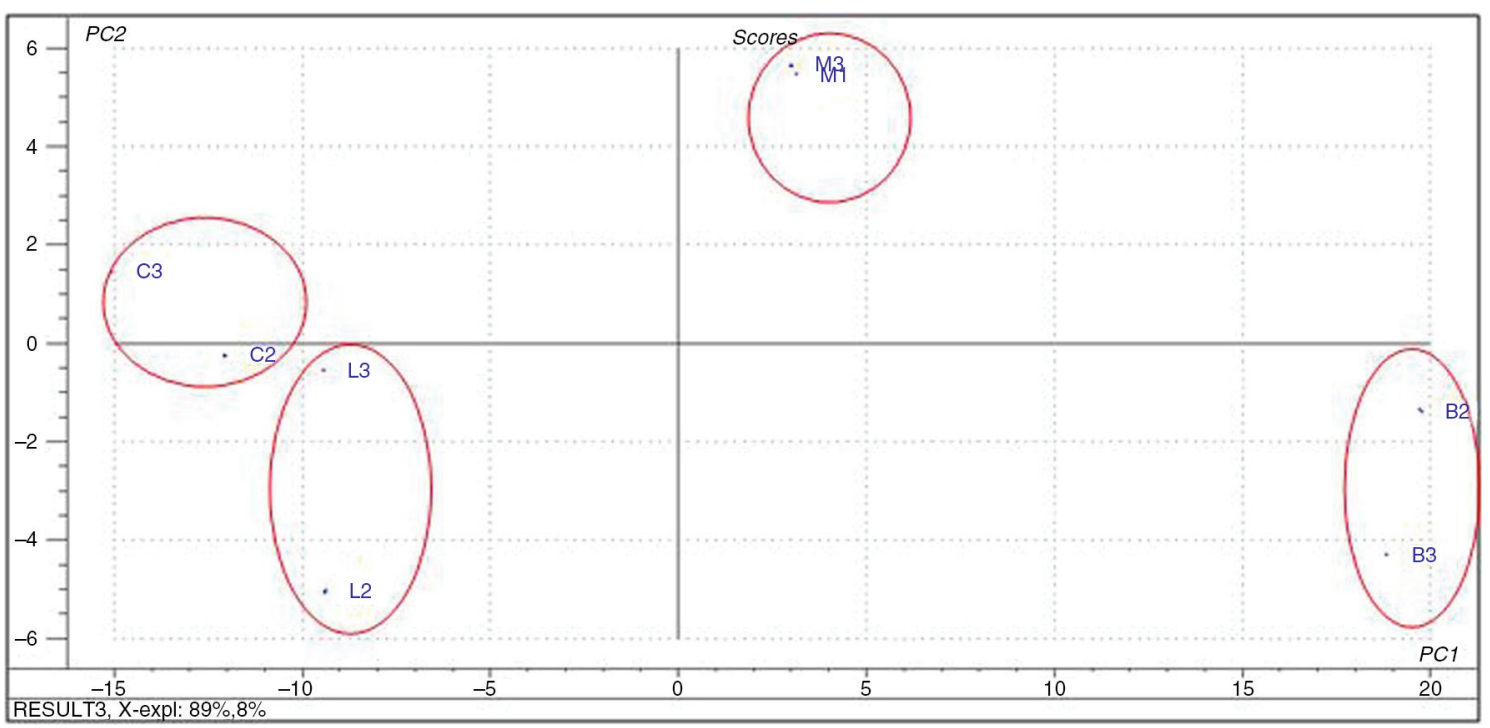

FIGURE 1. Score plot of PCA of the MAG derived from animal fats based on fatty acid composition. Abbreviations: L, lard; C, chicken fat; B, beef fat; M, mutton fat.

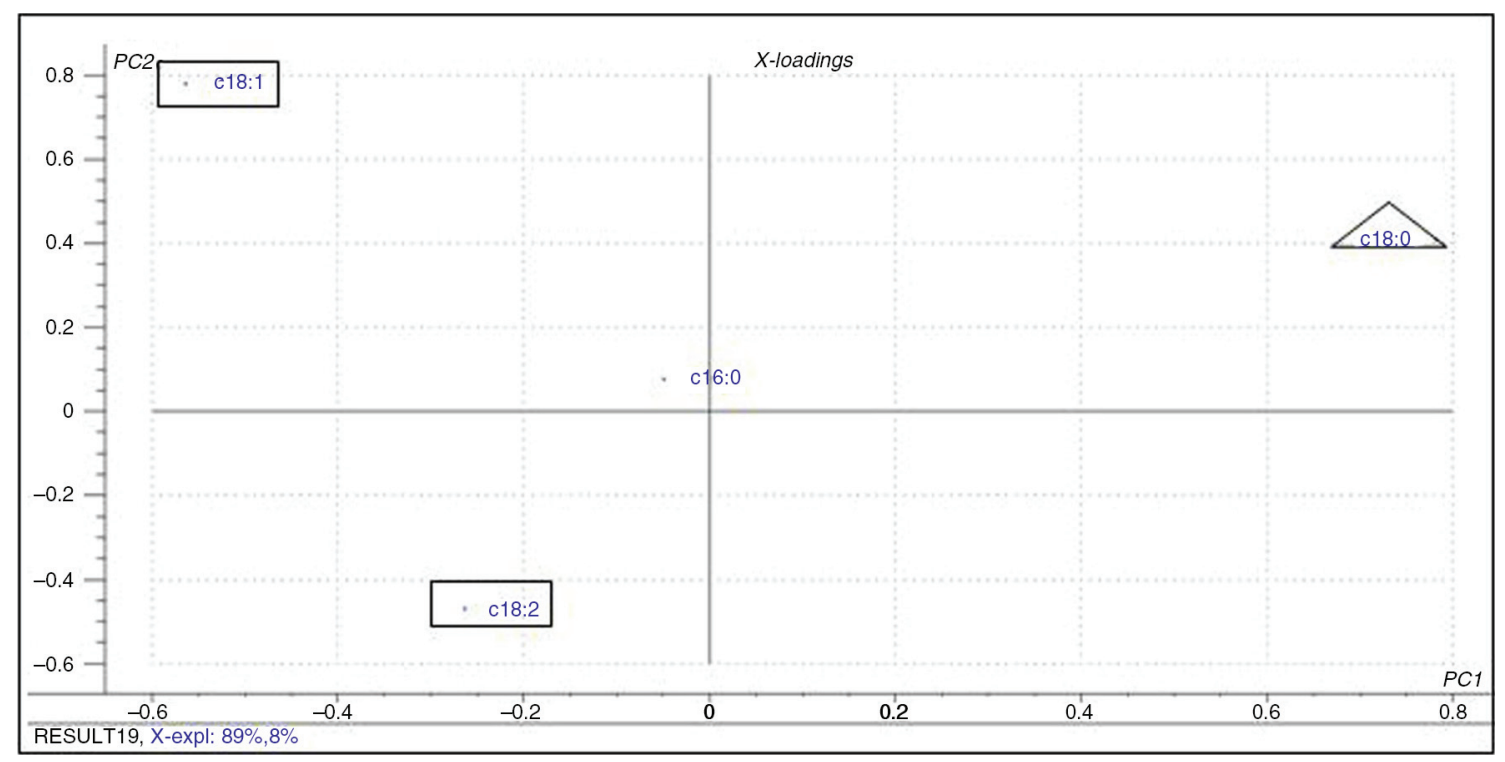

FIGURE 2. Loading plot of the PCA of the MAG derived from animal fats based on fatty acid composition. (PC1: $\Delta, \mathrm{PC} 2: \square)$.

\subsection{Fatty acid profiles of DAG}

The data presented in Table 2 compares the fatty acid distributional pattern of DAG derived from lard, chicken fat, beef fat and mutton fat. As noted before with MAG, the most dominant fatty acid of DAG derived from lard was oleic acid $(40.29 \%)$, followed by palmitic $(31.35 \%)$ and stearic $(14.92 \%)$. Similarly, the DAG of chicken fat was also found to have oleic acid $(47.24 \%)$ as the most dominant fatty acid, followed by palmitic (31.36\%) and stearic $(7.85 \%)$ acids. The DAG of chicken fat differed from that of lard by having differences in the proportions of several fatty acids. In addition, the occurrence of a small amount of arachidic acid in the DAG of chicken fat was noteworthy. DAG derived from beef and mutton fats differed considerably from those of lard and chicken fat by having stearic (36.49-38.57\%) as the major fatty acid (Table 2). As noted before in the case of MAG 
fatty acids, the DAG of beef fat and mutton fat also displayed lower contents of unsaturated fatty acids (30.99 to $36.13 \%)$ than saturated fatty acids (63.87 to $69.02 \%$ ). There were differences between the MAG of beef and mutton fats with regard to the occurrence of myristic, palmitoleic, and linoleic acids as these three fatty acids were totally absent in the MAG of mutton fat. Despite the observed differences, a clear differentiation among the DAG of different animal fats can be reached when these data are subjected to a multivariate data analysis technique such as PCA.

As listed in Table 2, fatty acids, namely myristic (14:0), palmitic $(\mathrm{C} 16: 0)$, palmitoleic $(\mathrm{C} 16: 1)$, stearic (C18:0), oleic (C18:1) and linoleic (C18:2) acids were found to occur in variable amounts in all the DAG derived from animal fats. When PCA was performed using these fatty acids as variables, a classification of DAG originating from different animal fats was established. The score plot of the fatty acids of DAG derived from animal fats shown in Figure 3 represent the projection of samples defined by principle component 1 (PC1) describing $87 \%$ of the variation while PC2 accounted for $9 \%$ of the variation, making up $96 \%$ of variance explained for the PC1 and PC2. According to the group separation illustrated in Figure 3, the DAG of lard and chicken fat were located in the lower left quadrant, and upper left quadrant, respectively. Their positions were well differentiated from the DAG of mutton fat and beef fat, which were located in the upper right quadrant and lower right quadrant, respectively. Fatty acid variables having strong influence on the group separation of the samples in the score plot could be traced from the analysis of the loading plot as presented in Figure. 4. As explained by Cordella et al. (2003), a variable which is farther from the origin of axis contributes most to the variation in the statistical model generated by PCA. According to the loading plot in Figure 4, out of the six fatty acids, stearic, oleic and linoleic acids were the most discriminating variables that influence the group separation into four different clusters.

\section{CONCLUSIONS}

This study investigated the application of GC-MS and EA-IRMS techniques for the discrimination of MAG and DAG derived from lard, chicken fat, beef fat, and mutton fat. Overall fatty acid data showed that the use of a single fatty acid as parameter may not be suitable to classify the MAG and DAG derivatives of different animal fats into distinct subclasses. Hence, the application of multivariate statistical techniques such as PCA would be required to classify them into different sub-categories. The outcome of the PCA showed that stearic, oleic and linoleic acids were the most discriminating parameters for the separation of MAG and DAG derivatives of lard from those of other animal fats. The significant differences in the values of $\delta^{13} \mathrm{C}$ of all animal fats have been proven to be good indicators for discriminating the MAG and DAG of lard from those of chicken fat, beef fat and mutton fat. This showed that the determination of the bulk carbon isotope ratio has considerable potential for the classification of fat derivatives of different animal origin.

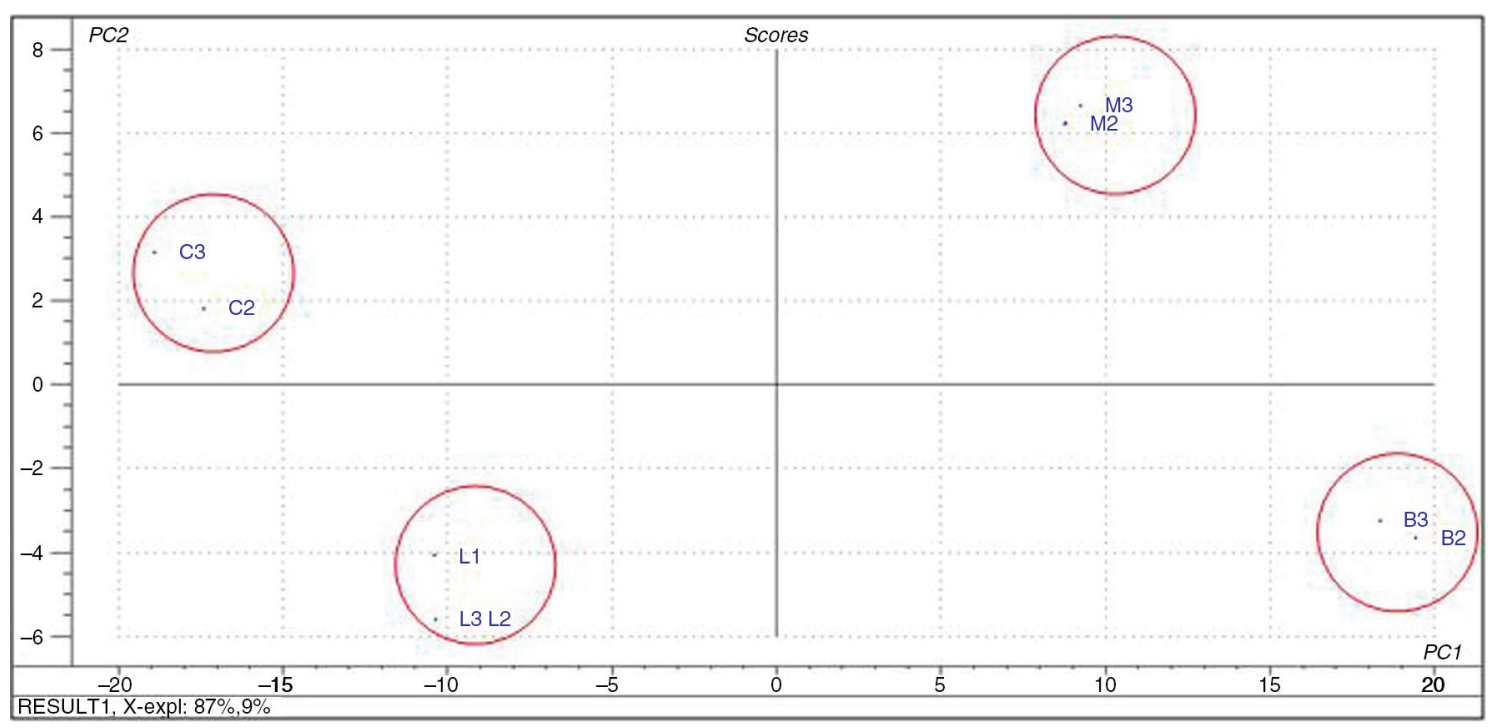

Figure 3. Score plot of the PCA of the DAG derived from animal fats based on fatty acid composition. Abbreviations: L, lard; C, chicken fat; B, beef fat; M, mutton fat. 


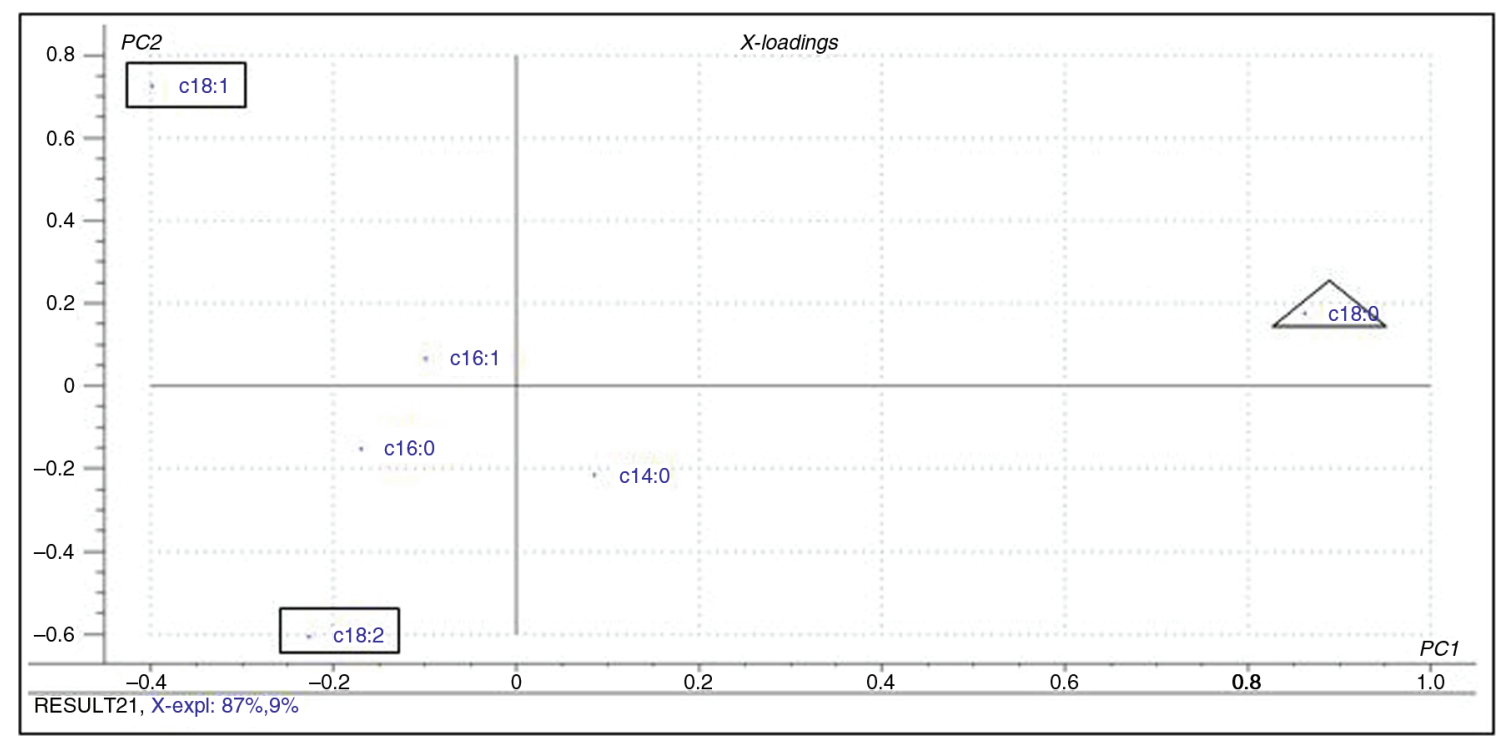

FIGURE 4. Loading plot of the PCA of the DAG derived from animal fats based on fatty acid composition. (PC1: $\Delta, \mathrm{PC} 2: \square)$

\section{ACKNOWLEDGEMENT}

The authors gratefully acknowledge the financial support received under the Research University Grants Scheme (Grant No. 02-01-11-1141 RU) of Universiti Putra Malaysia.

\section{REFERENCES}

AOCS. 2007. Official method and recommended practices of the American Oil Chemists' Society. 6th ed. American Oil Chemists' Society, Illinois.

AOAC 2007. Official methods of analysis of AOAC International. 18th ed. Association of Official Analytical Chemists, Washington, DC.

De Man JM, Lipids, in Principles of Food Chemistry. ( $3^{\text {rd }}$ edn.). Springer Science+Business Media, Inc. New York, 1999, pp. 33-110.

Destaillats F, Cruz-Hernandez C, Nagy K, Dionisi F. 2010. Identification of monoacylglycerol regio-isomers by gas chromatography-mass spectrometry. J. Chromatogr. 1217, 1543-1548. http://dx.doi.org/10.1016/j.chroma.2010.01.016.

Gil JH, Hong JY, Jung JH, Hong, J. 2007. Structural determination of monoacylglycerols extracted from marine sponge by atom bombardment tadem mass spectrometry. Rapid Commun. Mass Spectrum. 21, 1264-1270. http://dx.doi.org/ $10.1002 / \mathrm{rcm} .2948$

Deng L, Nakano H, Iwasaki Y. 2008. Direct separation of monoacylglycerol isomers by enantioselective high-performance liquid chromatography. J. Chromatogr. A, 1198-1199, 67-72. http://dx.doi.org/10.1016/j.chroma.2008.03.095.

Aursand M, Mabon F, Martin GJ. 2000. Characterization of farmed and wild salmon (Salmo salar) by a combined use of compositional and isotopic analyses. J. Am Oil Chem. Soc. 77, 659-666. http://dx.doi.org/10.1007/s11746-000-0106-5.

Bianchi G, Angerosa F, Camera L, Reneiro F, Anglia C. 1993. Stable carbon isotope ratios $(13 \mathrm{C} / 12 \mathrm{C})$ of olive oil components. J. Agric. Food Chem. 41, 1936-1940. http://dx.doi.org/10.1021/ jf00035a024.

Bojlul B, Monahan FJ, Moloney AP, Kiely PO, Scrimgeour CM, Schmidt, O. 2007. Alteration of the carbon and nitrogen stable isotope composition of beef by substitution of grass silage with maize silage. Rapid Commun. Mass Spectrom. 19, 1937-1942. http://dx.doi.org/10.1002/rcm.2007.

Cheng SF, Choo YM, Ma AN, Chuah CH. 2005. Rapid synthesis of palm-based monoacylglycerols. J. Am. Oil Chem. Soc. 82, 791-795. http://dx.doi.org/10.1007/s11746-005-1145-7.

Cheong L.Z, Hong Z, Yuan X, Xuebing X. 2010. Physical characterization of lard partial acylglycerols and their effect on melting and crystallization properties of blends with rapeseed oil. J. Agric. Food Chem. 57, 5020-5027. http://dx.doi. org/10.1021/jf900665h.

Chesson L, Tipple BJ, Erkkila BR, Cerling TE, Ehleringer JR. 2011. B-HIVE: Beeswax hydrogen isotopes as validation of environment. Part I: Bulk honey and honeycomb stable isotope analysis. Food Chem. 125, 576-581. http://dx.doi. org/10.1016/j.foodchem.2010.09.050.

Cordella CBY, Militão JSLT, Clément MC, Cabrol-Bass D. 2003. Honey characterization and adulteration detection by pattern recognition applied on HPAEC-PAD profiles. 1. Honey floral species characterization. J. Agric. Food Chem. 51, 3234-3242. http://dx.doi.org/10.1021/jf021100m.

Indrasti D, Che Man Y, Chin ST, Mustafa S, Mat Hashim D, Abdul Manaf M. 2010. Regiospecific analysis of mono- and diglycerides in glycerolysis products by GC $\times$ GC-TOF-MS. J. Am. Oil Chem. Soc. 87, 1255-1262. http://dx.doi.org/ 10.1007/s11746-010-1614-x.

Kamal-Eldin A, Anderson R. 1997. A multivariate study of the correlation between tocopherol content and fatty acid composition in vegetable oils. J. Am. Oil Chem. Soc. 74, 375-380. http://dx.doi.org/10.1007/s11746-997-0093-1.

Kelly SD, Rhodes C. 2002. Emerging techniques in vegetable oil analysis using stable isotope ratio mass spectrometry. Grasas Aceites. 53, 34 44. http://dx.doi.org/10.3989/gya. 2002.v53.i1.288.

Kelly S, Parker I, Sharman M, Dennis J, Goodall, I. 1997. Assessing the authenticity of single seed vegetable oils using fatty acid stable carbon isotope ratios. Food Chem. 59, 181-186. http://dx.doi.org/10.1016/S0308-8146(96)00286-5.

Liu X, Xu SP, Wang JH, Yuan JP, Guo LX, Li X, Huang XN. 2007. Characterization of ganoderma spore lipid by stable carbon isotope analysis: implications for authentication. Anal. Bioanal. Chem. 388, 723-731. http://dx.doi.org/10. 1007/s00216-007-1270-7. 
Marikkar JMN, Yanty NAM. 2014. Effect of chemical and enzymatic modifications on the identity characteristics of lard-Review. Int. J. Food Prop. 17, 321-330. http://dx.doi. org/10.1080/10942912.2011.631251.

Marikkar JMN, Lai OM, Ghazali HM, Che Man YB. 2001. Detection of lard and randomized lard as adulterants in RBD palm oil by differential scanning calorimetry. J. Am. Oil Chem. Soc. 78, 1113-1119. http://dx.doi.org/10.1007/ s11746-001-0398-5.

Naqiyah ANN, Marikkar JMN, Dzulkifly MH. 2013. Differentiation of lard, chicken fat, beef fat, and mutton fat by GCMS and EA-IRMS techniques. J. Oleo Sci. 63 , 459-464. http://dx.doi.org/10.5650/jos.62.459.

Osorio MT, Moloney AP, Schmidt O, Monahan FJ. 2011. Multi element isotope analysis of bovine muscle for determination of international geographical origin of meat. J. Agric. Food Chem. 59, 3285-3294. http://dx.doi.org/10.1021/ jf1040433.

Riaz MN, Chaudary MM. 2004. Halal Food Production. pp. 1-379. Florida: CRC press.

Rezaei K, Temelli F. 2000. Lipase-catalyzed hydrolysis of canola oil in supercritical carbon dioxide. J. Am. Oil Chem. Soc. 77, 903-909. http://dx.doi.org/10.1007/s11746-000-0143-0.
Shin EC, Craft BD, Pegg RB, Phillips RD, Eitenmiller RR. 2011. Chemometric approach to fatty acid profiles in Runner-type peanut cultivars by principal component analysis (PCA). Food Chem. 119, 1262-1270. http://dx.doi.org/10.1016/j. foodchem.2009.07.058

Simsek A, Bilsel M, Goren AC. 2012. 13C/12C pattern of honey from Turkey and determination of adulteration in commercially available honey samples using EA-IRMS. Food Chem. 130, 1115-1121. http://dx.doi.org/10.1016/j. foodchem.2011.08.017

Wood JD, Enser M, Fisher AV, Nute GR, Sheard PR, Richardson RR, Hughes SI, Whittington FM. 2008. Fat deposition, fatty acid composition and meat quality: A review. Meat Sci. 78, 343-358. http://dx.doi.org/10.1016/j.meatsci.2007.07.019.

Yanty NAM, Marikkar JMN, Che Man YB, Long K. 2011. Composition and thermal analysis of lard stearin and lard olein. J. Oleo Sci. 60, 333-338. http://dx.doi.org/10.5650/ jos.60.333.

Sudraud G, Coustard JM, Retho C. 1981. Analytical and structural study of some food emulsifiers by high performance liquid chromatography and off line mass spectrometry. J. Chromatogr. 204, 397-406. http://dx.doi.org/10.1016/ S0021-9673(00)81685-4. 